\title{
DESENVOLVIMENTO DE UMA FERRAMENTA PARA AVALIAČ̃̃O DA MATURIDADE PARA A SUSTENTABILIDADE ORGANIZACIONAL: UMA PROPOSIÇÃO TEÓRICO-METODOLÓGICA
}

\author{
Fábio Josende Paz ${ }^{1,2}$, Rejane Frozza ${ }^{2}$, Liane Mahlmann Kipper ${ }^{2 *}$ \\ ${ }^{1,2}$ Mestrando, Universidade de Santa Cruz do Sul (UNISC), Santa Cruz do Sul, Brasil \\ ${ }^{2}$ Programa de Pós Graduação em Sistemas e Processos Industriais, Universidade de Santa Cruz do Sul (UNISC), Santa Cruz do Sul, \\ Brasil
}

*E-mail: liane@unisc.br

\section{RESUMO}

Atualmente, as organizações necessitam adotar políticas e práticas sustentáveis, o que vem ocasionando uma maior busca e utilização de modelos sustentáveis. Contudo, as organizações não sabem se estão aptas a utilizar esta metodologia sustentável. Este artigo tem como objetivo apresentar uma proposta de metodologia para avaliar a maturidade e a educação para a sustentabilidade organizacional. Como fontes de informação utiliza-se a bibliografia para entender o "estado do conhecimento" em relação à sustentabilidade e explicativa quando ao modelo, que possibilitou o desenvolvimento de uma ferramenta de análise da maturidade, com foco na sustentabilidade, tendo como base conceitos do Triple Botton Line e o ciclo de aprendizagem vivencial. Como resultado, gerou-se um método que permite o diagnóstico das organizações e o respectivo posicionamento quanto ao grau de maturidade para a sustentabilidade, além de promover a educação e ser um indutor de mudanças e como complemento será desenvolvido um sistema computacional utilizando técnicas de usabilidade.

Palavras-chave: Maturidade. MESO. Sustentabilidade Organizacional.

\section{Introdução}

Atualmente, vivemos em um novo paradigma, o da sustentabilidade, no qual devemos pensar em um mundo holístico, participativo, com ética em suas relações. Neste contexto, as relações organizacionais têm causa e efeito no todo e as organizações precisam redefinir seus planejamentos e ações voltadas a este novo pensamento. Esta adesão a modelos mais sustentáveis requer uma postura não imediatista e sim uma visão de planejamento de curto, médio e longo prazo [1]. Para isso a utilização de modelos sustentáveis empresariais é imprescindível para a continuação e sucesso das organizações, contudo é necessário saber se a organização está pronta para este desafio.

Desta forma este artigo propõe um modelo teórico e metodológico para avaliar a maturidade e educação para a sustentabilidade organizacional e verificar se as organizações estão realmente prontas para implantarem modelos sustentáveis.

O artigo está organizado da seguinte maneira: a próxima seção apresenta aspectos teóricos sobre os temas envolvidos na pesquisa; a seção três aborda o método utilizado; a seção quatro descreve a proposição do modelo e os resultados encontrados até o momento. Finaliza apresentando as considerações finais, sugestões para trabalhos futuros e as referências utilizadas.

\section{Revisão de Literatura}

\subsection{Sustentabilidade nas organizações}

Sustentabilidade pode ser definida como uma abordagem de negócio que considera de forma equilibrada e holística os aspectos econômicos, sociais e ambientais gerando em longo prazo benefícios a gerações futuras e as partes interessadas "stakeholders" [2]. Diversos autores complementam informando que desde que o termo sustentabilidade surgiu no mundo dos negócios, um crescente número de empresas perceberam a importância da sustentabilidade para alavancar seus negócios [2-4]. Segundo Almeida [1] uma empresa para ser sustentável e competitiva atualmente deve buscar em todas suas ações e decisões a eco eficiência, produzir mais e melhor com menos poluição e menos uso de recursos naturais, além de ser socialmente responsável. Ignorar essa realidade custará sua existência mais cedo ou mais tarde.

Sustentabilidade parte também do diálogo, ouvir as pessoas é fator chave e primordial para que a organização consiga implantar esta nova política necessária a sua sobrevivência. Almeida [1] fala que se devem levar em consideração as opiniões e expectativas dos stakeholders, ou seja, 
instituições, indivíduos, empregados e suas famílias, consumidores, fornecedores, comunidades e outras empresas que com ela interagem. Ainda pode-se dizer que sustentabilidade, portanto, é colaboração e é evoluir perante a si mesmo, e evoluir não seria inovar? Segundo diversos autores a busca da sustentabilidade deve gerar indiscutivelmente inovações organizacionais, as empresas precisam reformular produtos, tecnologias, processos e muitas vezes modelos de negócios que transformam o cenário competitivo [5-7]. Almeida [1] complementa dizendo que cabe às empresas de qualquer porte descobrir novas formas de produzir bens e serviços que gerem mais qualidade de vida com menor quantidade de recursos naturais.

A sustentabilidade organizacional são as ações que as organizações realizam visando à promoção de programas sociais e à redução dos impactos ambientais e se mantendo economicamente viável no mercado [8]. O mesmo autor afirma que uma organização ecologicamente sustentável está agindo de forma socialmente responsável atendendo $\mathrm{o}$ interesse dos stakeholders que afetam ou são afetados por suas atividades, outros autores complementam e afirmam que a busca pela sustentabilidade não precisa e nem é financeiramente inviável como muitos empresários e organizações julgam ser, pensar e agir sustentavelmente pode reduzir custos e aumentar as receitas, sendo a base para inovações, assim sustentabilidade pode ser percebida como um diferencial competitivo para as organizações, proporcionando uma maior eficiência e ganhos de desempenho através da inovação [2,5,8]. Ainda Lameira et. al. [9] em seus estudos com 205 empresas abertas brasileiras demonstra em seus resultados que foi possível estabelecer que organizações que possuem condutas sustentáveis têm melhores desempenhos financeiros e menores riscos, portanto foi possível concluir que a maior sustentabilidade caminha junto com a melhor gestão, afirmando que sustentabilidade tem valor para as organizações, o que é também comprovado nos estudos de Noguti et. al. [10] com a empresa Natura que apesar de aplicar políticas sustentáveis é líder de mercado e seu faturamento vem aumentando a cada ano.

Nessa linha Wals and Schwarzin [6] afirmam que a sustentabilidade parte das pessoas envolvidas na organização e que é grande a importância da aprendizagem nos conceitos que envolvem a sustentabilidade e que é imprescindível educação dos colaboradores e para corroborar Oliveira et. al. [11] em seus estudos demonstram cinco princípios necessários para que ocorra uma melhor implantação da sustentabilidade nas organizações.

- Incentivar iniciativa voluntária dos profissionais da organização.

- Inclusão de profissionais motivados para a sustentabilidade e sua participação no planejamento estratégico.

- Desenvolvimento e implantação de indicadores estratégicos, táticos e operacionais (nos âmbitos social, econômico e ambiental).
- Estabelecer processo interno de participação dos diversos níveis hierárquicos na formulação dos objetivos e metas estratégicos vinculados à sustentabilidade organizacional.

- Estabelecer vínculo entre o plano de desenvolvimento de carreira ao engajamento dos profissionais à sustentabilidade organizacional.

Segundo Lehtonen [12] para que ocorra essa sustentabilidade nas organizações é necessário que todos os elos estejam bem, o financeiro para estar bem necessita que o social e o ambiental também estejam. Corroborando com outros autores [12-13], realizou-se um estudo com 32 micro e pequenas empresas da cidade de São Paulo - SP, onde constataram a dificuldade em implantar os conceitos da sustentabilidade e que é principalmente no elo social o maior problema e o principal motivo foi o desconhecimento por parte dos colaboradores de conceitos de sustentabilidade, além da falta de interesse e da percepção que é trabalho desnecessário, pois não impactará no resultado financeiro da organização, o que demonstra a necessidade de educação de todos os stakeholders, quando da implantação dessa metodologia. Para entender melhor essa questão da sustentabilidade, é preciso explicar melhor estes três elos: ambiental, financeiro e social e seu inter-relacionamento.

\subsection{Triple Botton Line}

A sobrevivência e o sucesso de uma organização estão diretamente relacionados à sua capacidade de atender as necessidades e as expectativas de seus clientes, as quais devem ser identificadas, entendidas e utilizadas para que os produtos possam ser desenvolvidos, criando o valor necessário para conquistá-los e retê-los. Por outro lado, para que haja continuidade em suas operações, a organização também deve atuar de forma responsável em relação à sociedade e às comunidades com as quais interage, contribuindo para o desenvolvimento socioambiental [14].

Baseado nas dimensões econômica, social e ambiental, a ideia baseia-se na correlação entre estas três dimensões, para que a sustentabilidade realmente aconteça. Internacionalmente essas dimensões são conhecidas como Triple Bottom Line (TBL) da sustentabilidade de um negócio [15], Elkington [16] criou o TBL para auxiliar as empresas no desenvolvimento sustentável: prosperidade econômica, justiça social e proteção ao meio ambiente, dentro de suas operações principais e essencialmente fazendo o salto da sustentabilidade teórica para a prática. $\mathrm{O}$ conceito TBL questiona e pondera sobre a necessidade de as empresa basearem suas decisões estratégicas neste tripé, onde deverão manter a sustentabilidade econômica do seu negócio ao gerenciar empresas lucrativas e geradoras de valor, também a sustentabilidade social estimulando atividades ligadas à educação, cultura, lazer, bem estar e justiça social da comunidade onde a empresa está inserida e tudo isso mantendo o cuidado com o meio ambiente através de cuidados ambientais 
como programas de reciclagem, preservação, dentre outros aspectos.

O TBL é um índice corporativo que se diferencia das demais por mensurar também as inter-relações entre as dimensões do desenvolvimento sustentável: eco-ambiental, ecosocial, socioambiental e eco-sócio-ambiental. Também adota o conceito de sustentabilidade do resultado triplo: melhorar o crescimento financeiro reduzindo os impactos ambientais negativos e atendendo às expectativas da sociedade [7].

Para uma organização estar plenamente conectada e alinhada com seus clientes é necessário que suas estratégias contemplem os ambientes econômicos, sociais e ambientais conforme descreve a Figura 1.

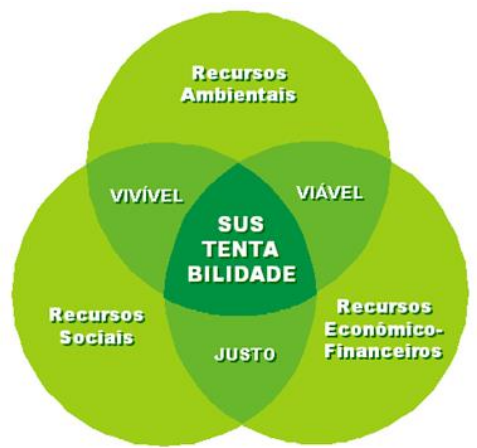

Figura 1. A sustentabilidade em suas dimensões ambientais, sociais e econômicofinanceiras [17]

Umas das maiores dificuldades é o entendimento das metodologias e sua aplicação, além do pouco conhecimento sobre sustentabilidade dos stakeholders. Como o modelo a ser criado tem o objetivo de ser um indutor de mudanças é necessário compreender alguns conceitos sobre educação para a sustentabilidade.

\subsection{Educação para a Sustentabilidade}

A sociedade é aprendiz e educadora ao mesmo tempo e está em constante mutação. Estamos migrando de um paradigma dominante onde $o$ conhecimento era fragmentado $e$ as especialidades não eram inter-relacionadas para um paradigma emergente onde unir, reintegrar, religar são atitudes pertinentes, onde a busca do generalista fica evidente. Este novo paradigma foca em um mundo holístico centrado em um pensamento sistêmico [18].

O autor ainda nos diz que a educação tem uma dimensão claramente social, de aprender com a experiência de outros, de saber conviver melhor com diversidades, apoiando o desenvolvimento das potencialidades de cada um e oferecer condições para a progressão do indivíduo.

Percebe-se que as organizações precisam dessa mudança em suas atitudes e pensamentos, para tanto é necessário usar este novo pensamento emergente na educação em que o processo de aprendizagem baseia-se nas experiências do aprendiz, neste caso, a própria empresa. Isso demonstra que indicadores não podem ser estáticos, fixos e imutáveis, eles precisam reintegrar, unificar, sendo indutores de mudanças na organização.

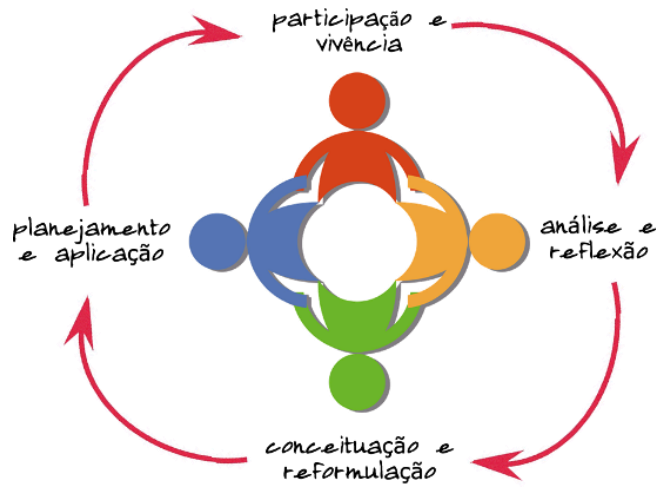

Figura 2. Ciclo de aprendizagem vivencial [19].

A figura 02 demonstra o ciclo de aprendizagem vivencial que é uma metodologia de aprendizado que permite à pessoa vivenciar uma experiência concreta, que possibilitará que ela caminhe do relato da experiência vivida e chegue a uma ação concreta para aplicar nas situações reais do cotidiano [19-20]. O autor diz ainda que a base da aprendizagem vivencial é a experimentação e que a noção de criação e transferência de conhecimento é muito mais do que uma mera reprodução e sim um processo que passa pela reflexão, crítica e internalização do que é vivido.

Este conceito aplicado nas organizações pode demostrar a importância da empresa aprender constantemente. Observa-se também a necessidade de seus sistemas gerenciais serem mais dinâmicos e ágeis. Assim a utilização deste conceito é para que realmente os sistemas sejam indutores de mudanças significativas na organização, não só mostrando resultados, mas também ensinando e mostrando caminhos a seguir, podendo ser um caminho para o desenvolvimento de um sistema computacional que indique ações mais sustentáveis.

\subsection{Usabilidade}

O sistema computacional a ser criado tem como prioridade a simplicidade e facilidade na sua utilização, gerando intenção de uso, sem a necessidade de profissionais treinados para sua aplicação, facilitando assim seu uso por empresas de todos os portes, mas principalmente as micros e pequenas empresas. Para isso utilizaremos as técnicas de usabilidade que segundo Nielsen e Loranger [21] é um atributo de qualidade relacionado à facilidade em usar algo, ou seja, a rapidez com que os usuários podem aprender a usar alguma coisa. Ainda os mesmos autores afirmam que é necessário projetar para o usuário, ou seja, escutar os usuários e torná-los centro de seu projeto. Projetar interfaces elaboradas e não convencionais pode ser bonito, porém a chave para um bom sistema é a simplicidade 
aliada a um design. Nielsen e Loranger [21] e Bevan, Claridge \& Petrie [22] afirmam a importância em testar o sistema com usuários reais, dando-lhes tarefas e os observá-los, esse é o teste mais eficiente, facil e barato de fazer.

A melhoria da usabilidade apresenta muitos benefícios os quais Bevan, Claridge \& Petrie [22], listam:

Aumento da eficácia e eficiência: um sistema adaptado ao modo como o utilizador age permite uma interação mais eficaz e eficiente;

- Maior produtividade: permite que o utilizador se concentre na tarefa e não na ferramenta, aumentando o seu desempenho em consequência da qualidade da interação;

- Menor necessidade de formação: um sistema com um bom nível de usabilidade, projetado com base no utilizador final facilita a aprendizagem;

- Melhoria da aceitação: gera maior confiança sistemas bem projetados com funcionalidades que facilitem a informação para o usuário;

- Apoio a utilizadores com menos competências tecnológicas;

- Redução de erros.

Resumindo usabilidade é quando analisamos como o usuário utiliza o sistema e como são organizadas as tarefas que ele realiza, ou seja, podemos conhecer como as outras tarefas afetam o trabalho do usuário e podemos entender a melhor maneira de apresentar o ambiente para o mesmo e que este tenha atrativos e benefícios que o façam utilizar o sistema. Portanto a utilização de técnicas de usabilidade no sistema proposto é para melhorar desenhar o ambiente composto principalmente pelo formulário de pesquisa junto ao usuário como também apresenta-lo da melhor forma aos seus usuários

\section{Metodologia}

Este trabalho se originou por uma pesquisa exploratória que, segundo Barros [23], busca a aproximação e a familiaridade com o tema. Também é descritiva na medida em que descreve as características conhecidas e busca criar uma teoria explicativa para o método construído. Conforme Santos [24] pode-se indicar como fontes de informação a bibliografia para entender o "estado do conhecimento" em relação à sustentabilidade nas organizações.

\section{Resultados e discussões}

Nesta seção encontra-se a proposta de modelo de maturidade e educação para a sustentabilidade organizacional (MESO) confeccionado para atingir os objetivos propostos no estudo (figura 3). Segundo Siqueira [25] e Assis et. al. [26] maturidade organizacional pode ser entendida como os processos são explicitamente definidos, gerenciados, medidos e controlados. Ainda que avaliar a maturidade de algum aspecto da organização auxilia no reconhecimento de oportunidades de melhoria e no planejamento e monitoração das ações para a implantação desta.

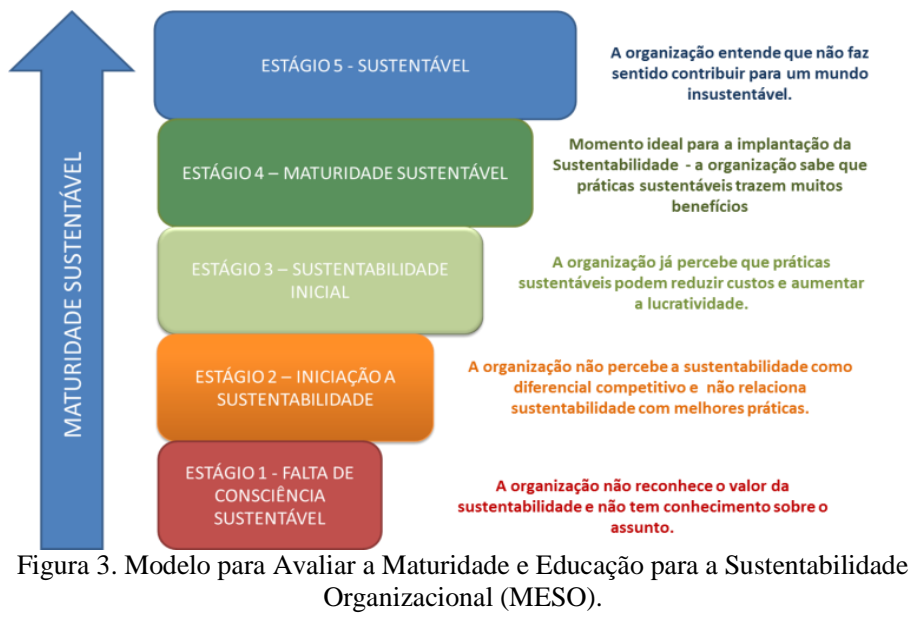

A sustentabilidade organizacional é um conjunto de ações e práticas alinhadas com o Triple Botton Line - TBL e suas três dimensões: Econômica / Financeira; Social e Ambiental considerando suas correlações. O modelo para avaliar a Maturidade e Educação para a Sustentabilidade Organizacional (MESO) é uma forma da organização avaliar o seu estágio de maturidade relativo à sustentabilidade, para verificar se a organização está pronta para implantar uma forma de agir mais sustentável. O MESO é dividido em cinco estágios e dividos nas três dimensões do TBL.

O MESO começa no Estágio 1, o qual é chamado de Falta de Consciência Sustentável. Neste estágio, a organização não reconhece o valor da sustentabilidade, existe pouco ou inexiste conhecimento sobre a sustentabilidade e a dimensão financeira apresenta-se mais relevante em sua gestão do que as demais dimensões propostas no tripé da sustentabilidade.

O Estágio 2 é chamado de Iniciação à Sustentabilidade. Já existem práticas sustentáveis, porém poucas e sem correlação entre os pilares do TBL, a gerência não percebe a sustentabilidade como diferencial competitivo e não relaciona sustentabilidade com maior lucratividade. O conhecimento sobre sustentabilidade já existe porém não difundido na organização, as ações sociais e ambientais são vistas como custos adicionais e sustentabilidade é tratada da "boca para fora", pois apenas cumpre-se a legislação do setor.

No Estágio 3 que é chamado de Sustentabilidade Inical os gestores já percebem que práticas sustentáveis podem reduzir custos e aumentar o retorno financeiros das operações, as ações sociais, ambientais e financeiras possuem uma ligação e 
objetivos concretos, neste nível, já é possível à implantação de metodologia sustentável com uma boa probabilidade de sucesso.

O Estágio 4 é chamado de Maturidade Sustentável. É nesse nível que se considera o melhor momento de implantar modelos sustentáveis na sua totalidade na organização, pois os gestores estão convictos que práticas sustentáveis trazem muitos benefícios e que é imprescindível para o crescimento da empresa, além de implantarem em suas estratégias a sustentabilidade como fator chave de sucesso; são desenvolvidos produtos e serviços com olhar sustentável os quais agrega valor a todos os envolvidos.

O mais alto nível é o Estágio 5 que se chama Sustentável. A organização adota práticas sustentáveis por que entende que não faz sentido contribuir para um mundo insustentável, as iniciativas sustentáveis vêm da organização como um todo. Os stakeholders são ouvidos e o diálogo e os questionamentos são as principais ferramentas sustentáveis e a inovação é constante. Na sequência do estudo, com a intenção de coletar a melhor informação possível, foi elaborado um quadro relacionando os estágios do Modelo MESO com a metodologia TBL, conforme descreve a figura 4.

A figura 4 foi inspirada no artigo de Assis et. al. [26], onde o mesmo avaliou a maturidade da organização para inovações em quatro níveis com suas pontuações. Ela também apresenta como o modelo MESO entende seus cinco estágios em relação às dimensões do TBL, assim como, demonstra o que o modelo levará em consideração para a posterior classificação da organização em relação a sua maturidade. Para proporcionar a educação continuada, a metodologia MESO ainda incorpora preceitos de Kolb [19-20] através de seu ciclo de aprendizagem vivencial conforme figura 5.

\section{ESTÁGIOS DA MESO}

\begin{tabular}{|c|c|c|c|c|c|c|}
\hline & & $\begin{array}{l}\text { ESTÁGIO } 1 \text { - FALTA } \\
\text { DE CONSCIÊNCIA } \\
\text { SUSTENTÁVEL }\end{array}$ & $\begin{array}{l}\text { ESTÁAGIO 2 - } \\
\text { INICIAÇÄO A } \\
\text { SUSTENTABILIDADE }\end{array}$ & $\begin{array}{l}\text { ESTACIOB - } \\
\text { SUSTENTABLIDADE } \\
\text { INICIAL }\end{array}$ & $\begin{array}{l}\text { ESTACIO 4- } \\
\text { MATURIDADE } \\
\text { SUSTENTÁVEL }\end{array}$ & $\begin{array}{l}\text { ESTÁGIO } 5 \text { - } \\
\text { SUSTENTÁVEL }\end{array}$ \\
\hline $\begin{array}{l}\text { D } \\
\text { I } \\
\text { M } \\
\text { E } \\
\text { N }\end{array}$ & 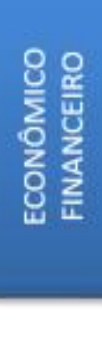 & $\begin{array}{l}\text { Foco predominante na } \\
\text { esfera econỏmica, o } \\
\text { objetivo principal é a } \\
\text { maximização do lucro. } \\
\text { Apesar disto é } \\
\text { economicamente } \\
\text { ineficiente. }\end{array}$ & $\begin{array}{c}\text { Foco ainda predominante } \\
\text { na esfera económica, } \\
\text { porém acő́es } \\
\text { socioeconómicas } \\
\text { começam a surgir e } \\
\text { economicamente a } \\
\text { organizaçăo começa a } \\
\text { crescer. }\end{array}$ & $\begin{array}{c}\text { A empresa observa que } \\
\text { pode obter vantagens } \\
\text { econômicas pela adosăo de } \\
\text { uma postura sustentável, } \\
\text { tais como, reduçäo de } \\
\text { custos, maior eficiência } \\
\text { operacional, porém as } \\
\text { práticas se encontram em } \\
\text { um nivel de maturidade } \\
\text { baixa }\end{array}$ & $\begin{array}{l}\text { A empresa começa a colher } \\
\text { bons resultados com a } \\
\text { implementaç̆o de práticas } \\
\text { sustentáveis. Os clientes } \\
\text { identificam a empresa como } \\
\text { sustentável e ocorre uma } \\
\text { valorizaçdo da marca por } \\
\text { conta disto. Começa a } \\
\text { identificar novas } \\
\text { oportunidades lucrativas de } \\
\text { negócios }\end{array}$ & $\begin{array}{l}\text { A empresa investe em } \\
\text { inovaçăo e no } \\
\text { desenvolvimento de } \\
\text { negócios sustentáveis. } \\
\text { Possui patentes registradas } \\
\text { e lucra com as inovaç̋̃es } \\
\text { sustentáveis. }\end{array}$ \\
\hline $\begin{array}{l}\mathrm{E} \\
\mathrm{S}\end{array}$ & 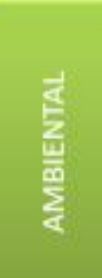 & $\begin{array}{l}\text { Desconhece as questöes } \\
\text { ambientais do setor, não } \\
\text { possui práticas } \\
\text { sustentáveis. }\end{array}$ & $\begin{array}{l}\text { Atende a legislaçắo do setor } \\
\text { e começa a implantaçăo de } \\
\text { práticas sustentaveis, } \\
\text { porém em sua maioria } \\
\text { açő́es corretivas. }\end{array}$ & $\begin{array}{c}\text { Medidas proativas comecam } \\
\text { a ser implementadas, mas a } \\
\text { maioria ainda são as } \\
\text { corretivas, Introduçăo de } \\
\text { práticas de reduçăo de } \\
\text { consumo de recursos năo } \\
\text { renováveis. }\end{array}$ & $\begin{array}{l}\text { Medidas proativas săo a } \\
\text { maioria. A empresa dá } \\
\text { importância à utilização de } \\
\text { fontes renováveis de } \\
\text { energia. O setor de P\&D já } \\
\text { apresenta demandas para } \\
\text { desenvolvimento de } \\
\text { produtos verdes. }\end{array}$ & $\begin{array}{l}\text { A empresa é considerada } \\
\text { referència em muitas } \\
\text { práticas de sustentabilidade. } \\
\text { Nảo há o uso de recursos se } \\
\text { afetar sua existência. }\end{array}$ \\
\hline B & 离 & $\begin{array}{c}\text { Praticamente não há } \\
\text { interaçăo com a } \\
\text { sociedade. A organizaçăo } \\
\text { năo sabe sobre o assunto. }\end{array}$ & $\begin{array}{l}\text { Pouca interaçăo entre } \\
\text { comunidade e empresa. } \\
\text { Näo existe a preocupaçăo } \\
\text { de desenvolvimento da } \\
\text { comunidade local. }\end{array}$ & $\begin{array}{l}\text { Relacionamento incipiente } \\
\text { com a comunidade do } \\
\text { entorno. Introduçåo de } \\
\text { práticas para o } \\
\text { desenvolvimento da } \\
\text { comunidade e melhoria da } \\
\text { qualidade de vida dos } \\
\text { trabalhadores. }\end{array}$ & $\begin{array}{l}\text { Relacionamento } \\
\text { desenvolvido com a } \\
\text { comunidade do entorno. } \\
\text { Parceria com ONGs e } \\
\text { associaçóes locais para } \\
\text { fomento ao } \\
\text { desenvolvimento da } \\
\text { comunidade. Funcionários } \\
\text { motivados com o trabalho e } \\
\text { com a politica de } \\
\text { sustentabilidade da } \\
\text { empresa. }\end{array}$ & $\begin{array}{l}\text { Relacionamento bem } \\
\text { desenvolvido com todos os } \\
\text { stakeholders, incluindo } \\
\text { parceria com Centros de } \\
\text { Pesquisa, universidades e } \\
\text { órgăo reguladores. }\end{array}$ \\
\hline
\end{tabular}

Figura 4. Correlacionamento MESO X TBL 


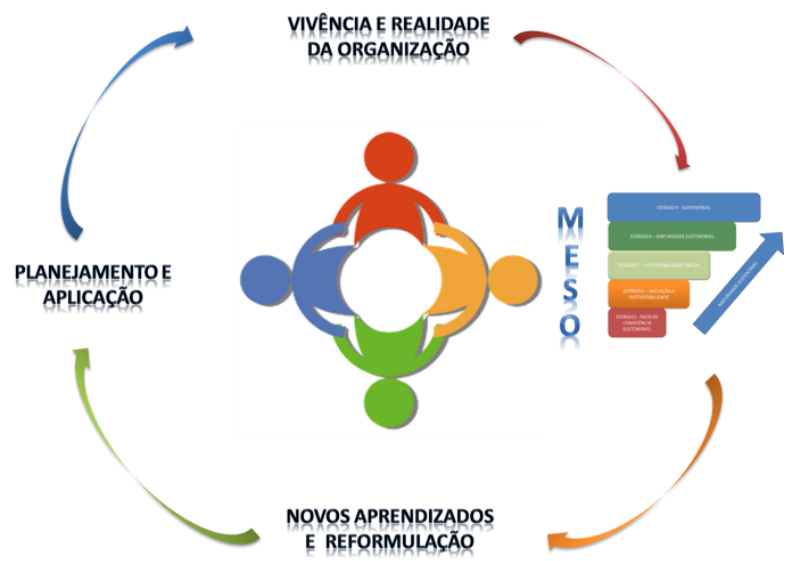

Figura 5. MESO e o Ciclo de Aprendizagem Vivencial.

$\mathrm{Na}$ figura 5, visualiza-se a proposta de ferramenta completa, perfazendo todas as fases. Primeiramente, é preciso identificar a vivência e a realidade da organização a ser estudada para determinar em qual nível de maturidade e educação para a sustentabilidade organizacional a mesma encontra-se; posteriormente, a descoberta de novos conhecimentos e aprendizados sobre sustentabilidade e a reformulação de conceitos sobre o assunto, gerando o planejamento de ações para a organização avançar em níveis de maturidade da sustentabilidade. A partir das ações realizadas, é possível gerar um novo ambiente e uma nova realidade organizacional. A ferramenta possibilitará verificar a evolução da organização em busca da sustentabilidade plena.

Como complemento da metodologia será desenvolvido um sistema computacional para facilitar a utilização do MESO, sendo importante ressaltar que este utilizará técnicas de usabilidade que segundo Nielsen [27] é componente importante e podem prevenir muitos problemas e reduzir custos de projetos, além de promover satisfação aos usuários com uma maior flexibilidade e uma maior interação.

\section{Conclusões}

O presente artigo buscou apresentar a sustentabilidade como diferencial competitivo para as organizações, demonstrando a importância da implantação deste novo paradigma. Para que isto ocorra, propõe-se um novo modelo que será capaz de auxiliar as organizações no planejamento de suas práticas sustentáveis, além de promover a educação para a sustentabilidade sendo um indutor de mudanças organizacionais, porém algumas limitações surgem como o modelo é apenas uma proposição se faz necessário à validação do modelo com organizações.

Como sugestão para trabalhos futuros, é preciso o aprofundamento dos estudos e a criação da metodologia completa com suas devidas etapas demonstradas e validadas em organizações do segmento do agronegócio. O desenvolvimento de um sistema computacional utilizando técnicas de usabilidade para facilitar a divulgação e utilização deste modelo prósustentabilidade junto às organizações também será realizado dando continuidade ao trabalho.

\section{Agradecimentos}

À UNISC pelo apoio à pesquisa via edital, o FAP e pela concessão da bolsa de pós-graduação CAPES.

\section{DEVELOPMENT OF A TOOL FOR EVALUATION OF MATURITY FOR ORGANIZATIONAL SUSTAINABILITY: A THEORETICAL- METHODOLOGICAL PROPOSAL}

ABSTRACT: Today, organizations need to adopt sustainable policies and practices, which has caused a higher search and use of sustainable models. However, organizations do not know if they are able to use this sustainable methodology. This article aims to present a proposed methodology to assess the maturity and education for organizational sustainability. As information sources bibliography is used to understand the "state of knowledge" in relation to sustainability and explanatory when the model, which enabled the development of an analysis tool of maturity, with a focus on sustainability, based on concepts of Triple Bottom Line and the experiential learning cycle. As a result, created a method that allows diagnosis of organizations and their placement on the degree of maturity for sustainability, and promote education and be a promoter of changes and in addition will develop a computer system using usability techniques .

Keywords: Maturity. MESO. Organizational sustainability.

\section{Referências}

[1] ALMEIDA, F. O bom negócio da sustentabilidade. São Paulo: Nova Fronteira, 2002.

[2] LANGE, D. E.; BUSCH, T.; CEBALLOS, J. D. Sustaining Sustainability in organizations. Journal of Business Ethics, p.151-156, 2012.

[3] Global Reporting Iniciative Portal (GRI). About GRI. Disponível em: <https://www.globalreporting.org/information/about-gri/what-is-

GRI/Pages/default.aspx> Acesso em: 29 de março de 2014.

[4] CAMPOS, L. M. S. et al. Relatório de sustentabilidade: perfil das organizações brasileiras e estrangeiras Segundo o padrão da Global Reporting Initiative. Gestão e Produção, Vol.20, n.4, p.913-926, 2013. 


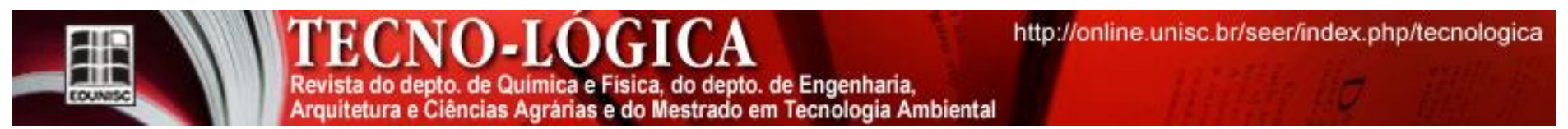

[5] NIDUMOLU, R.; PRAHALAD, C. K.; RANGASWAMI, M.R. Por que a sustentabilidade é hoje o maior motor da inovação?. Harvard Business Review, Vol.87, n.9, 2009

[6] WALS, A. E. J..; SCHWARZIN L. Fostering organizational sustainability through dialogic interaction. The Learning Organization, Vol.19, n.1, p.11-27, 2012.

[7] SILVEIRA; M.A. Strategic management of innovation towards sustainable development od brazilian electronic. Journal Technologic Management \& innovation, Vol.8, 2013

[8] ARAÚJO, G. C. et al. Sustentabilidade empresarial: Conceitos e Indicadores Congresso Online Convibra, 2006.

[9] LAMEIRA, V.J. et al. Sustentabilidade, valor, desempenho e risco no mercado de capital brasileiro. Revista Brasileira de Gestão de Negócios, Vol.15, n. 46 , p.76-90, 2013

[10] NOGUTI, M.B. et al. Sistema de Gestão Ambiental - Natura Cosméticos S/A. In: CONGRESSO NACIONAL DE EXCELÊNCIA EM GESTÃO, 2008, Niterói. Anais... Niterói: CNEG, 01 a 02 de agosto de 2008.

[11] OLIVEIRA, L.R. et al. Sustentabilidade: da evolução dos conceito à implementação como estratégia nas organizações. Produção, Vol.22, n.1, p.70-82, 2012 .

[12] LEHTONEN, M. The environmental-social interface of sustainable development: capabilities, social capital, institutions. Ecological Economics, Vol. 49, p.199-214, 2004.

[13] CAREON, L. H.; SILVA, S. F. Sustentabilidade ambiental nas organizações: Sustentabilidade empresarial para a micro e pequena empresa. São Paulo: SEMEAD, set/2010.

[14] FUNDAÇÃO NACIONAL DA QUALIDADE (FNQ). Conceitos Fundamentais da Excelência em Gestão. Disponível em: <http://www.fnq.org.br/site/292/default.aspx > Acesso em: 24 Agosto de 2013.

[15] FUNDAÇÃO DOM CABRAL (FDC). Abordagens para a Sustentabilidade nas Organizações. Disponível em: 〈http://www.fdc.org.br/pt/publicacoes > Acesso em: 30 dezembro de 2013.

[16] ELKINGTON, J. Triple bottom line revolution: reporting for the third millennium. Australian CPA, Vol.69, p.75, 1999.

[17] ALLEDI FILHO, C. O tripé da sustentabilidade: Apostila do curso MBA Gestão de Negócios Sustentáveis. LATEC Business School, 200

[18] MORAN, J. M. A educação que desejamos: novos desafios e como chegar lá. Campinas: Papirus, 2009.

[19] KOLB, D. A. Psicologia organizacional: uma abordagem vivencial. São Paulo: Atlas, 1990.

[20] KOLB LEARNING STYLES. Disponível em:

<http://www.businessballs.com/kolblearningstyles.htm>. Acesso em: 03 setembro de 2014.

[21] NILESEN, J.; LORANGER; H. Usabilidade na web: Projetando websites com qualidade. Rio de Janeiro: Elsevier, 2007.

[22] BEVAN, N.; CLARIDGE, N.; PETRIE, H. Tenuta: Simplified Guidance for Usability and Accessibility. In: Proceedings of HCI International. Las Vegas, 2005.
[23] BARROS, A. J. S.; LEHFELD, N.A.S. Fundamentos de metodologia científica: um guia para iniciação científica. São Paulo: Pearson Education do Brasil, 2000.

[24] SANTOS, A. R. Metodologia científica: a construção do conhecimento. Rio de Janeiro: DP\&A, 3.ed, 2000.

[25] SIQUEIRA, J. O Modelo de Maturidade de Processos: como maximizar o retorno dos investimentos em melhoria da qualidade e produtividade. In: $60^{\circ}$ ABM CONGRESS. Belo Horizonte (MG), Jul/2005.

[26] ASSIS; B.F.S.P. et al. Metodologia para análise de maturidade de inovações sustentáveis. Sistemas \& Gestão, Vol.7, p.416-427, 2012.

[27] NIELSEN, J. Usability 101: Introduction to Usability. (jan/2012) Disponível em: http://www.nngroup.com/articles/usability-101-introduction-tousability/ Acesso em: 04 de setembro de 2014. 